\title{
LEITURAS DE JERUSALÉM E DA CHINA EM DUAS NARRATIVAS DE EÇA DE QUEIRÓS'
}

\section{READINGS OF JERUSALEM AND CHINA IN TWO NARRATIVES BY EÇA DE QUEIRÓS}

Osmar Pereira Oliva²

RESUMO: O Oriente sempre foi um topos para a imaginação ocidental e um leitmotiv para a criação artística. Por um lado, foram construídas referências cristãs, a partir das representações de Jerusalém; por outro, representaram-se fantasias sobre a riqueza fácil e sobre a liberdade moral e sexual que poderiam ser encontradas na China. Estas leituras das representações de Jerusalém e da China tomam como base os conceitos de "orientalismo" desenvolvidos por Edward Said e Isabel Pires de Lima; e de "fantástico", segundo Carlos Roberto F. Nogueira e Maria do Carmo Castelo Branco de Sequeira, a fim de se discutir como Eça de Queirós representou, ironicamente, esses lugares imaginários.

PALAVRAS-CHAVE: Eça de Queirós. Jerusalém. China. Orientalismo. Fantástico.

ABSTRACT: The Orient has always been a topos for Western imagination and a leitmotiv for artistic creation. In one sense, Christian references were built from the representations of Jerusalem; in other sense, fantasies about the easy wealth and about the moral and sexual freedom that could be found in China were represented. These readings of the representations of Jerusalem and China are based on the concepts of "orientalism" developed by Edward Said and Isabel Pires de Lima; and "fantastic", according to Carlos Roberto F. Nogueira and Maria do Carmo Castelo Branco de Sequeira, in order to discuss how Eça de Queirós represented, ironically, these imaginary places.

KEYWORDS: Eça de Queirós. Jerusalem. China. Orientalism. Fantastic.

\section{Orientalismo e dimensăo fantástica}

Isabel Pires de Lima, discutindo o orientalismo na Literatura Portuguesa, afirma que, no século XIX, multiplicam-se as obras de narrativas de viagens em que o Oriente "torna-se um topos para a imaginação ocidental e um leitmotiv da criação artística. Proliferam na Europa a pintura e a literatura orientalistas, a ponto

\footnotetext{
${ }^{1}$ Artigo recebido em 15/04/2020 e aceito para publicação em 18/06/2020.

2 Professor de Literaturas de Língua Portuguesa nos cursos de Letras e no mestrado em Estudos Literários da Universidade Estadual de Montes Claros - Unimontes. E-mail: osmar.oliva@unimontes.br.
} 
de se poder falar de uma semiótica oriental" (LIMA, 2001, p.437). Para essa autora, o Oriente aparece como metáfora de uma pátria subjetiva, espiritual, onde cada um encontra o que procura, por meio de uma busca interior, uma viagem imaginária e até estática. Alguns desses autores conheceram, de fato, o Oriente, como Eça de Queirós, que viajou para o Egito na época da inauguração do canal de Suez, em 1869. Segundo Luís Manuel de Araújo:

A viagem por terras do Oriente durou pouco mais de 2 meses: Eça desembarcou em Alexandria no dia 5 de novembro, seguindo logo para o Cairo, onde visitou os monumentos islâmicos e os vestígios da civilização faraônica existentes nos arredores da grande metrópole cairota. (...) Durante a sua permanência no Egito, Eça de Queirós foi anotando em pequenos cadernos as impressões colhidas nas visitas aos locais históricos, tendo desenvolvido mais cuidadosamente os seus apontamentos em meias folhas de papel almaço, nas quais também incluiu algumas idéias que o ambiente local lhe ia sugerindo (In: Campos Matos, 1988, p.220-221).

Seguindo as anotações do que ia vendo e experimentando em terras orientais, predomina na escrita eciana uma visão "realista" do espaço, dos costumes e das tradições e da religião, como é perceptível em $A$ Relíquia. Já em $O$ Mandarim, Eça nos apresenta uma visão estereotipada da China, assim como o Ocidente a concebia, na época. Nesse sentido, vale ressaltar o importante livro Orientalismo, de Edward Said (2001), para o qual o Oriente foi concebido pelos europeus como um (pre)conceito e menos como uma experiência. Já na introdução de sua obra, Said (2001:13) afirma que "O Oriente era quase uma invenção européia, e fora desde a Antigüidade um lugar de romance, de seres exóticos, de memórias e paisagens obsessivas, de experiências notáveis (SAID, 2001, p.13)."

Alguns autores do século XIX que viajaram para o Oriente e escreveram sobre suas impressões de viagens demonstram, por meio da ficção produzida, um sentimento de angústia, de insatisfação, de desencanto, pois chegaram a esse lugar primeiro como europeu, colonizador, ou americano, e, depois, como homens. Segundo Said:

Interdisciplinar, Săo Cristóvăo, UFS, v. 33, jan-jun, p. 155-171, 2020 D0l: https://doi.org/10.47250/intrell.v33il.14183 
O Oriente é olhado, posto que o seu comportamento quase (mas nunca totalmente) ofensivo tem origem em um reservatório de infinita particularidade; o europeu cuja sensibilidade passeia pelo Oriente é um observador, nunca envolvido, sempre afastado, sempre pronto para novos exemplos daquilo que a Description de l'Égypte chamou de "bisarre jouissance". O Oriente torna-se um quadro vivo de estranheza (SAID, 2001, p.112).

Outros dados importantes na obra de Said são a visão científica que muitos autores do século XIX tinham sobre o Oriente, como uma necessidade de conhecê-lo para classificá-lo e, contraditoriamente, a necessidade individual do autor de reinterpretar o Oriente para compreender a si mesmo e, não, um lugar estranho, um povo e uma cultura exóticos. Mesmo assim, percebemos pelo menos três tipos de narrativas sobre o Oriente: a) com uma visão mais realista (na perspectiva histórica, da colonização, por exemplo); b) como relatos de peregrinações; c) com descrições fabulosas, nas quais o Oriente aparece como um espetáculo.

A Relíquia, publicado em 1887, é considerado pelos críticos da obra de Eça de Queirós como o mais fantasista dos seus romances, juntamente com O Mandarim (1897) e A Cidade e as Serras (1901). Discutindo a presença do fantástico na ficção queirosiana, Maria do Carmo Castelo Branco de Sequeira afirma que, com o Romantismo, começou a desenvolver-se um tipo específico de ficção, acompanhado muitas vezes por reflexão doutrinária, a que se denominou de ficção fantástica.

A narrativa queirosiana apresenta elementos que, de certa forma, estão mais ligadas ao Romantismo, já que o próprio conceito de fantástico, embora ainda esteja em construção, é feito pela negação da realidade, como escreve Maria do Carmo Castelo Branco de Sequeira, "'impossible'; 'unreal'; 'nameless'; 'formless'; 'shapeless'; 'unknow'(...)" (SEQUEIRA, 2002, p. 217).

Essa ficção, derivada do termo "fantasia", abrangeria tudo o que não privilegiasse uma representação realista e estaria vinculada aos ideais românticos de retorno ao passado, às origens. Para essa autora, o fantástico possui um vínculo estreito com a literatura popular, com as narrações orais, as quais mais acentuadamente narram estórias maravilhosas, de encantamento e de aparições sobrenaturais.

Interdisciplinar, Săo Cristóvăo, UFS, v. 33, jan-jun, p. 155-171, 2020 D0I: https://doi.org/10.47250/intrell.v33i1.14183 
O lluminismo contribuiu significativamente para o recrudescimento desse tipo de literatura, uma vez que possibilitou a "revisão" crítica dos dogmas cristãos e a valorização da cultura popular, a crença em aparições. Por outro lado, o século XIX apresentou um certo desencanto com a ciência, com o progresso e com a racionalidade, o que motivou o culto do irracional, do ideal, das representações místicas como forma de escapismo.

O fantástico é, pois, um tipo de ficção que se caracteriza pela irrupção do mistério, do inexplicável, do inadmissível, que se introduz na "vida real" ou no "mundo real", ou, ainda, na "inalterável legalidade cotidiana" das personagens, conforme afirma Tzvetan Todorov. Segundo esse autor, "o fantástico (...) dura apenas o tempo de uma hesitação: hesitação comum ao leitor e à personagem, que devem decidir se o que percebeu depende ou não da 'realidade', tal qual existe na opinião comum" (TODOROV, 1975, p. 47-48).

Alargando a discussão para a questão dos desejos sexuais, Todorov aponta que uma das figuras mais recorrentes nesse tipo de literatura é a do diabo, encarnação do que é profano, proibido, interdito. Em oposição, representam-se símbolos incompatíveis com o desejo sexual, como esculturas sacras ou a cruz, por exemplo.

Ainda são poucos os estudos realizados sobre $O$ mandarim, e menos ainda sobre a função do fantástico. Dentre os que já a analisaram, destacam-se Óscar Lopes, que estudou a figura do diabo; Beatriz Berrini, que elaborou um ensaio sobre "Os prefácios ensaísticos de Eça de Queiroz"; e Maria do Carmo Castelo Branco de Sequeira, que trabalhou com o fantástico na obra de Eça Queirós, investigando a sua função na poética do romance. Para Sequeira, a dimensão fantástica é “(...) um constante cruzamento de um modelo de mundo ficcional verossímil (que se pretendia representação do mundo factual) com aspectos do absurdo, do insólito, do macabro, do desconhecido e do sobrenatural (...)" (SEQUEIRA, 2002, p. 444).

Portanto, o caráter fantástico de uma narrativa se dá pela fuga da realidade, entrando no terreno do improvável e do impossível, levando o leitor a sentir um estranhamento à medida que o mundo real vai se tornando desconhecido, ou seja, parte-se de algo real para se atingir o sobrenatural. 


\section{0 Oriente como topos erótico}

Em $A$ relíquia, Teodorico narrador nos informa que uma tarde, ao escurecer, cerrou os olhos e viu surgir um homem nu, colossal, tisnado, de cornos, olhos vermelhos e reluzentes, com um rabo infindável. Nessa passagem, o leitor é posto entre o sono e a vigília, o real e a imaginação, e acompanha a personagem e o diabo até o monte da crucificação de Jesus Cristo.

Além de erotizado, o diabo torna-se o guia de Teodorico pelo Egito, apresentando-Ihe as deusas Vênus, Milita, Ísis e as delícias da vida terrena. Em contraposição, a imagem de Cristo é o seu antípoda, pois pregava a mortificação da carne, usando a cruz escura para esmagar a terra.

Ainda que o romance $A$ Relíquia possa ser lido sob a perspectiva do fantástico, aqui nos deteremos apenas em discutir algumas representações de Jerusalém como metáfora de negação ou questionamento do cristianismo. A narrativa se vale do flash-back para tentar recompor as memórias do narrador-personagem, como se percebe nas primeiras páginas do romance, momento em que Teodorico explica por que escreveu o livro de sua vida:

\footnotetext{
Decidi compor, nos vagares deste Verão, na minha quinta do Mosteiro (antigo solar dos condes de Lindoso), as memórias da minha vida (...)

Em 1875, nas vésperas de Santo Antônio, uma desilusão de incomparável amargura abalou o meu ser: por esse tempo minha tia, D. Patrocínio das Neves, mandou-me do Campo de Sant'Ana, onde morávamos, em romagem a Jerusalém (...) e uma grande mudança se fez nos meus bens e na minha moral (QUEIRÓs, s/d, p. 11).
}

A partir dessas primeiras informações, o leitor é despertado para o interesse de saber que eventos ocorreram ao narrador que mudaram a sua vida. A curiosidade do leitor é ainda mais aguçada porque é evocada a cidade de Jerusalém, tão presente em nosso imaginário ocidental e cristão. No entanto, ao contrário das narrativas confessionais, em que, geralmente, as qualidades do narrador são idealizadas, o narrador se expõe como um "herói" hipócrita, interesseiro e aproveitador, além de antecipar que sua viagem ao Oriente lhe trouxe desilusão e amargura.

Interdisciplinar, Sằo Cristóvầo, UFS, v. 33, jan-jun, p. 155-171, 2020 D0I: https://doi.org/10.47250/intrell.v33i1.14183 
Durante uma reunião entre familiares e amigos, realizada na casa de D. Patrocínio, os convivas falam de seus desejos e sonhos. Teodorico, em tudo submisso às vontades de sua Titia, esperando com essa servilidade beata e hipócrita ser agraciado com a fortuna dela, já que era o seu único e legítimo herdeiro, é interpelado sobre suas ambições. Propenso aos gozos carnais e libidinosos, o protagonista responde que desejaria conhecer Paris, alegando que visitaria as igrejas. Tendo sua ideia reprovada por parte da Titi, o Dr. Margaride sugere que a viagem seja feita à Terra Santa:

- la à Terra Santa, D. Patrocínio! la à Palestina, minha Senhora! la ver Jerusalém e o Jordão! Queria eu também estar um momento de pé, sobre o Gólgota, como Chateaubriand, com o meu chapéu na mão, a meditar, a embeber-me, a dizer "salve!". E havia de trazer apontamentos, minha senhora, havia de publicar impressões históricas. Ora aí tem V. Exa onde eu ia... la a Sião (QUEIRÓs, s/d., 50).

A fala do Dr. Margaride ecoa como uma opinião comum aos intelectuais do século XIX: viajar para o Oriente para o descrever em narrativas de viagens e assim reavivar no imaginário ocidental o gosto pelo exótico, a fascinação pelas ruínas de cidades e templos antigos e até mesmo pelas novas experiências eróticas. É nesse sentido que Teodorico encara a proposta. A princípio, pensou que fosse possível conhecer a França e seus prazeres. Quando vê seus planos mudarem de direção, procura descobrir uma maneira de aproveitar bem a sua peregrinação pelo Oriente. Sob o viés da ironia, o autor Eça de Queirós parece problematizar a visão ingênua e a ignorância dos ocidentais em relação ao Oriente, pois Teodorico nem mesmo sabe onde fica Jerusalém, mas começou a considerar que,

para chegar a esse solo de penitência, tinha de atravessar regiões amáveis, femininas e cheias de festa. Era primeiro essa bela Andaluzia, terra de Maria Santíssima, perfumada de flor de laranjeira, onde as mulheres só com meter dois cravos no cabelo, e traçando um xale escarlate, amansam o coração mais rebelde (...) Era adiante Nápoles - e as suas ruas escuras, quentes, com retábulos da Virgem, e cheiran- 
do a mulher como os corredores dum lupanar. Era depois mais longe ainda a Grécia: (...) as mulheres tinha conservado lá o esplendor da sua forma e o encanto do seu impudor... Jesus! O que eu podia gozar! (QUEIRÓS, s/d., p. 52).

Teodorico imagina o Oriente como o lugar das delícias carnais, em tudo oposto ao imaginário religioso da Titi Patrocínio e de muitos ocidentais, ainda hoje. Para muitos ocidentais, uma romaria a Jerusalém significaria um grande marco de suas existências, pois permitiria ao viajante ver alguns trechos por onde Jesus Cristo teria caminhado e visitar o monte da crucificação ou o túmulo onde o Messias estivera sepultado. Jerusalém, no imaginário cristão, representa a pátria celeste, um lugar de origem, para onde se deseja retornar. Segundo o profeta Isaías, no capítulo 62:

Por amor de Sião, me não calarei e, por amor de Jerusalém, não me aquietarei, até que saia a sua justiça como um resplendor, e a sua salvação, como uma tocha acesa. As nações verão a tua justiça, e todos os reis, a tua glória; e serás chamada por um nome novo, que a boca do Senhor designará. Serás uma coroa de glória na mão do Senhor, um diadema real na mão do teu Deus. Nunca mais te chamarão Desamparada, nem a tua terra se denominará jamais Desolada; mas chamar-te-ão Minha-Delícia; e à tua terra, Desposada; porque o Senhor se delicia em ti (BÍBLIA Sagrada, 1999, p.1152-1153).

A essas imagens, de cidade iluminada e glorificada, lugar de delícias, o narrador queirosiano contrapõe outras, de cunho decadentista e naturalista, desconstruindo essa visão espiritualizada do profeta Isaías: "Jerusalém é uma vila turca, com vielas andrajosas, acaçapada entre muralhas de lodo, e fedendo ao sol sob o badalar de sinos tristes." (QUEIRÓs, s/d, p. 12).

Enquanto para Isaías Jerusalém é o lugar da espera, do cumprimento de uma profecia, para Teodorico é a certeza de uma desilusão, de uma amargura. Maria Helena Nery Garcez (1997), utilizando o salmo 122 e o capítulo 60 do Livro do Profeta Isaías, já apontou algumas visões de Jerusalém, contrapondo as imagens de "Cidade da Paz", "A Bem Edificada" às imagens tristes e deca- 
dentes construídas pelo narrador queirosiano. Segundo Garcez: "Tudo parece levar a crer que Eça de Queirós quis reservar para o espaço do sonho as imagens positivas e amáveis de Jerusalém, como que a dizer-nos que o cristianismo, assente sobre o judaísmo, teria sido um sublime ideal para a humanidade, uma perfeita religião, se fosse praticável; porém, já no próprio sonho, começava a mostrar-se imperfeita." (GARCEZ, 1997, p. 378).

Aparecida de Fátima Bueno (2000), em sua tese de doutorado "As imagens de Cristo na Obra de Eça de Queirós" retoma essas visões de Jerusalém, a partir dos apontamentos de Garcez, reafirmando a dessacralização dessa cidade símbolo do cristianismo. Para Bueno, o Cristo é posto em segundo plano na narração, aparecendo apenas como coadjuvante de sua própria história.

Aqui, em vez de contrapor visões de espaços geográficos: Lisboa e Jerusalém, procuro discutir a simbologia desses lugares para a personagem-narrador, um sujeito que, enquanto está no ocidente, tem os seus desejos controlados e interditos pela igreja católica, no romance representado pela severa D. Patrocínio. A viagem a Jerusalém é, pois, uma forma de Teodorico libertar-se dessa vigilância religiosa.

O Oriente, preconcebido pela personagem como um lugar distante e triste, passa a ser a única saída para a sua liberdade sexual, o que concorda com o pensamento de parcela significativa do mundo ocidental. Segundo Luiz Nazário, "a experiência da viagem, real ou imaginária, revela-se uma necessidade do homem." (NAZÁRIO, 2005, p. 222). Apropriadamente, Nazário afirma que a viagem é uma metáfora da vida.

Enquanto para o cristão a peregrinação a Jerusalém seria um retorno ao centro de Israel, tomando o significado da ascese e da purificação, para Teodorico, um português hipocritamente católico, essa peregrinação significa um martírio, pois Jerusalém representa para ele tudo o que ele abomina na Titi Patrocínio. Talvez por isso, por meio do fantástico, ele passa a acompanhar a via crúcis do Cristo, sentindo ele mesmo os castigos carnais imputados ao Messias.

Significativamente, Eça de Queirós constrói algumas cenas em que o diabo aparece como um companheiro de Teodorico, narrando-Ihe as experiências luxuriosas: 
(...) o Diabo rompeu a contar-me animadamente os cultos, as festas, as religiões que floresciam na sua mocidade. Toda esta costa do Grande Verde, então, desde Biblos até Cartago, desde Elêusis até Mênfis, estava atulhada de deuses. Uns deslumbravam pela perfeição da sua beleza, outros pela complicação da sua ferocidade. Mas todos se misturavam à vida humana, divinizando-a: viajavam em carros triunfais, respiravam as flores, bebiam os vinhos, defloravam as virgens adormecidas. (...) Aí todas as mulheres, matronas ou donzelas, se vinham um dia prostituir nos bosques sagrados, em honra da deusa Milita (QUEIRÓs, s/d., p. 67).

Depois de um longo diálogo em que expõe os prazeres carnais a Teodorico, o diabo lamenta: "Mas aparecera este carpinteiro de Galileia - e logo tudo acabara." (QUEIRÓs, s/d., p. 68).

Tenho discutido em outras leituras que Eça de Queirós revela, por meio de sua ficção, uma intensa preocupação com o destino de Portugal, atrasado econômica e politicamente em relação ao restante da Europa.

Em A Relíquia, duas questões fulcrais para uma reflexão sobre o atraso de Portugal podem ser apontadas; primeiro, a religiosidade irracional, que impede o progresso e o desenvolvimento da ciência, personificada no romance por D. Patrocínio, cujos horizontes se restringem aos altares de adoração, na sua limitação de católica tradicional e intransigente. Segundo, a ociosidade da personagem Teodorico, que, semelhante ao um ator de teatro, representa para a Titi e seus amigos uma farsa, quase convencendo a si mesmo de sua carolice.

Teodorico recebeu uma boa formação, desde os 7 anos, quando, órfão, é trazido para a casa de sua tia. Forma-se em Direito, mas nada faz para conseguir os meios de sua sobrevivência. $O$ que ele deseja mesmo é que a tia arrebente para que herde sua fortuna. Talvez por isso Eça de Queirós não permita que ele traga de Jerusalém a coroa de espinhos forjada para ser a relíquia da Titi, o que Ihe garantiria a herança tão almejada. Se ele obtivesse essa riqueza fácil, não saberia o que fazer com ela.

Não é por acaso que, depois de desconstruir o cristianismo, o romance apresenta uma certa retomada de consciência, ao final da narrativa, quando, olhando no espelho, Teodorico vê o 
Cristo saltar de dentro dele, fazendo-o refletir sobre a realidade e sobre a sua moralidade. Hesitante, o protagonista indaga ao leitor se não teria sido melhor afirmar que o embrulho pardo que entregou a Titi era mesmo uma relíquia santa, e que a camisola da inglesa Mary era a camisa de Maria Madalena.

A meu ver, Eça de Queirós recupera esse português hipócrita e malandro, pois quando Crispim, a sua primeira afeição de infância, Ihe convida para ir à igreja, ele responde: Olha, Crispim, eu nunca vou à missa... Tudo isso são patranhas... eu não posso acreditar que o corpo de Deus esteja todos os domingos num pedaço de hóstia de farinha. Deus não tem corpo, nunca teve... Tudo isso são idolatrias, são carolices... Digo-te isto rasgadamente... Podes fazer agora comigo o que quiseres, Paciência!" (QUEIRÓS, s/d., p.204-205).

A franqueza de Teodorico convence Crispim de sua sinceridade e os aproxima ainda mais. A seguir, outra conquista se efetiva, decorrente desse processo de transformação por que passa o protagonista. Lembremo-nos das primeiras linhas dessa narrativa, quando o narrador afirma suas mudanças nos bens e na moral. Por um lado, perdeu a fortuna da Titi, por outro lado, tornou-se um sujeito moral. Quando é interpelado por Crispim sobre os seus sentimentos a respeito de D. Jesuína, Teodorico responde: "Amor, amor, não... Mas acho-a um belo mulherão: gosto-lhe muito do dote; e havia de ser um bom marido." (QUEIRÓS, s/d., p. 205).

O final do romance confirma a vitória desse homem que recobra a consciência e abandona suas aventuras amorosas, suas hipocrisias e ociosidade. Assim, Jerusalém é apresentada no romance como uma cidade decadente, suja, feia porque representa para o narrador a origem do cristianismo, que o impediu de gozar os prazeres da vida e herdar a fortuna da Titi. No entanto, a caminho de Jerusalém, existe um outro Oriente, Alexandria, o Egito, lugares de delícias, onde o viajante pode gozar os prazeres da carne sem o peso dos valores morais da sociedade ocidental, como imaginou e experimentou Teodorico.

\section{0 imaginário da riqueza fácil}

Em O mandarim, Eça de Queirós problematizou, mais uma vez, o par ociosidade/ação. Teodoro, um funcionário público, segue uma rotina difícil de suportar, até que é convidado pelo diabo 
a tocar uma campainha, matar um mandarim e obter dele a fortuna. Inicialmente, o dinheiro propiciou a essa personagem um reconhecimento público e o gozo da vida mundana. Enquanto oferece festas suntuosas, Teodorico tem o respeito da sociedade; quando deixa de usufruir da riqueza do mandarim, todos se afastam e se esquecem dele. Movimento explorado pelo narrador para ironizar a postura da sociedade lisbonense.

Por outro lado, esse fantasioso Teodoro tem uma iluminação interior a que o narrador chama de consciência, capaz de julgar esse comportamento e até a si próprio, motivo que o leva a planejar a viagem à China para devolver à família do mandarim a fortuna que lhe fora tomada. Nessa viagem, a personagem presencia e narra a decadência e o abandono na China por meio de imagens com as quais o leitor do século XIX não estava acostumado. A consciência se personifica para tentar mostrar ao personagem a conseqüência de suas ações:

(...) Quando, depois de jantar, sentindo ao lado o aroma do café, eu me estirava no sofá, enlanguescido, numa sensação de plenitude, elevava-se logo dentro de mim, melancólico como o coro que vem de um ergástulo, todo um sussurro de acusações:

- E todavia tu fizeste que esse bem-estar em que te regalas, nunca mais fosse gozado pelo venerável $\mathrm{Ti}$ Chin-Fu!...

Debalde eu replicava à Consciência, lembrando-lhe a decrepitude do Mandarim, a sua gota incurável... Facunda em argumentos, gulosa de controvérsia, ela retorquia logo com furor:

- Mas, ainda na sua atividade mais resumida, a vida é um bem supremo: porque o encanto dela reside no seu princípio mesmo, e não na abundância das duas manifestações! (...) (QUEIRÓS, 1970, p. 1053).

Seu espírito positivista, no entanto, não aceitava que tudo isso estivesse acontecendo, e negava que o dinheiro fosse de algum ente sobrenatural (fosse ele o mandarim, o diabo ou Deus). Por isso, diz que "O teu grande nome de Consciência não me assusta! És apenas uma perversão da sensibilidade nervosa. Posso eliminar-te com flor de laranja!" (QUEIRÓS, 1970, p. 1053-1054). 
A ideia de ter levado a miséria a crianças faz com que o narrador busque na religião um "perdão". No entanto, por não acreditar em Deus, pediu a Nossa Senhora das Dores que concedesse alívio. Passou a rezar, mas era "(...) mais uma consolação fictícia que os que possuem tudo inventaram para contentar os que não possuem nada... (...)" (QUEIRÓs, 1970, p. 1055).

Apesar das descrições de uma China fantástica, com comidas exóticas, riqueza, palácios e uma cultura diferente atraírem inicialmente o narrador, quando prossegue sua viagem, indo para os bairros chineses, sai do esplendor para a imundície, solo lamacento, ruas empoeiradas, um fedor e vê um velório de um mandarim. Inicia-se um processo de desmitificação, mas até aqui, não houve desapontamento. No Templo do Céu, Teodoro vê mais elementos fantásticos:

\begin{abstract}
Ao passar junto ao Templo do Céu, vejo apinhada num largo uma legião de mendigos; tinham por vestuário um tijolo preso à cintura num condel; as mulheres, com os cabelos entremeados de velhas flores de papel, roíam ossos tranqüilamente; e cadáveres de crianças apodreciam ao lado, sob o vôo dos moscardos. Adiante topamos com uma jaula de traves, onde um condenado estendia, através das grades, as mãos descarnadas, à esmola... Depois Sá-Tó mostrou-me respeitosamente uma praça estreita: aí sobre pilares de pedra, pousavam pequenas gaiolas contendo cabeças de decapitados: gota a gota ia pingando delas um sangue espesso e negro... (QUEIRÓs, 1970, p. 1063-1064).
\end{abstract}

Percebe-se que a passagem tem características realistas/ naturalistas. A preocupação do autor se volta para a desconstrução do imaginário que é atribuído ao Oriente, pois aqui as imagens descritas provocam a quebra da idéia que se tem de uma terra maravilhosa, ideal. Neste momento, sente uma melancolia de estar ali isolado no "mundo bárbaro" e estranho, pois começa a perceber as mazelas do local, e passa a ver a China com outros olhos, se importando mais com sua terra.

Óscar Lopes discute que o diabo apareceu por causa da ambição de Teodoro e no final só para "(...) Ihe negar a satisfação do seu remorso (...)" (LOPES, 1997, p. 466), de voltar atrás. De qualquer modo, isso vai reforçar o arrependimento demonstrado 
em outras passagens, e desestimula qualquer um de seguir seu exemplo: "' Só sabe bem o pão que dia a dia ganham as nossas mãos: nunca mates o Mandarim!'” (QUEIRÓS, 1970, p. 1081). Aqui, Eça reforça o tom moralizante de sua narrativa.

A personagem Teodoro viajou para o Oriente para completar seu vazio, já que sua consciência estava punindo-o pela morte do mandarim. Teodoro segue a religião só no mundo dos sonhos, enquanto que, "acordado", ele segue a razão. E notamos, também, que ele só se sente português depois que se vê em outra terra, por isso sente falta de conviver com seus "iguais" civilizados.

Carlos Roberto F. Nogueira, em um interessante estudo sobre o diabo no imaginário cristão (1986), realiza um levantamento das primeiras representações simbólicas do diabo, a partir da tradição hebraica, responsável pela gestação do cristianismo, que sistematizou e determinou a figura, atividades e esfera de ação do diabo. Quase sempre, ele é a representação do mal, o tentador, o acusador, o juiz, o ladrão de almas. $\mathrm{O}$ cristianismo bipolarizou a escolha do homem: o Bem = Deus, luz, claridade, salvação; o Mal = o diabo, escuridão, trevas, perdição. Segundo Nogueira:

Qualquer que fosse o poder de Satã, era privilégio de cada cristão a capacidade de the opor resistência. A permissão concedida por Deus aos demônios de colocar os cristãos à prova era simplesmente para que estes pudessem cobrir os espíritos malignos de vergonha e, ao mesmo tempo, reforçar a sua própria fé (NOGUEIRA, 1986, p.25).

Em toda a parte se vê o diabólico. O imaginário popular está repleto de suas configurações, algumas vezes associadas à mulher, uma vez que os textos bíblicos têm afirmado que a muIher está mais propensa ao mal que o homem. No entanto, segundo Nogueira, o diabo utiliza múltiplos e criativos disfarces, como um homem galante, como uma bela mulher, incitando à luxúria, como um padre ou como um mercador, cabendo a um santo (um homem de caráter e coração puros) o poder de desmascarar esse "ator brilhante". O diabo também poderá se apresentar sob a forma de um animal ou mesclando formas humanas com uma natureza bestial. Esse imaginário contribui para reforçar o aspecto monstruoso e deformador do anjo do mal. 
Aspecto interessante é que "o Romantismo transformará Satã no símbolo do espírito livre, da vida alegre, não contra uma lei moral, mas segundo uma lei natural, contrária à aversão por este mundo pregada pela Igreja. Satanás significa liberdade, progresso, ciência e vida". (NOGUEIRA, 1986, p.80). Nesse sentido, em alguns textos do século XIX, o diabo passou a ser representado como o amigo do homem - inimigo de Deus - rebelião contra a fé e moral tradicional, revelando a descrença do homem na vontade divina, e, no entanto, uma crença na sua purificação por via do sofrimento, que é uma transição para a espiritualidade.

Se, por um lado, o diabo configura-se como um ser malvado, em tudo oposto a Deus e ao cristianismo, ligando-se pois, à crença na salvação da alma, por outro, no plano psicológico, torna-se o símbolo da libido, sem a qual não há o desabrochar do humano. Deve-se ressaltar o seu caráter paradoxal, pois, ao mesmo tempo que o diabo mostra a escravidão que espera aquele que fica cegamente submisso ao instinto, ele representará, também, uma libertação das amarras morais e das convenções sociais, sobretudo as de cunho religioso, que impedem o homem de viver a felicidade terrena em sua plenitude.

No Dicionário de símbolos, Chevalier et Gheerbrant discutem a representação do diabo, afirmando que

[t]odo o papel do diabo é esse: espoliar o homem, tirar-lhe a graça de Deus, para então submetê-lo à sua própria dominação. É o anjo caído, com suas asas roídas, que quer partir as asas de todo criador. Ele é a síntese das forças desintegradoras da personalidade. O papel do Cristo, ao contrário, é de arrancar o gênero humano ao poder do diabo pelo mistério da cruz. A cruz do Cristo liberta os homens, i. e., põe de novo nas suas mãos, com a graça de Deus, a livre disposição deles mesmos, de que uma tirania diabólica os havia privado.Enquanto divisor, desintegrador, o diabo preenche uma função que é a antítese exata da função do símbolo, que é de reunir, integrar (grifos nossos) (CHEVALIER ET GHEERBRANT, 1997, p.337).

No contexto pós-iluminista, que despertou a consciência crítica e menos crédula nos dogmas religiosos, principalmente do 
Catolicismo, Eça de Queirós parece "brincar" com as representações do diabo, seja para "revisar" a crença cega na religião, seja para satirizar o imaginário popular construído em torno desse símbolo do mal. Retomando nossas reflexões, a partir de Carlos Roberto F. Nogueira,

[a] apresentação do elemento demoníaco sob uma forma animal ou mesclando formas humanas e animais contribuía para salientar a sua natureza bestial, de acordo com a orientação canônica, mas também constituía um costume tradicional: o de representar seres sobrenaturais de modo monstruoso, por meio da combinação de elementos diversos da Natureza (NOGUEIRA, 1986, p. 57-58).

Em $A$ relíquia, o diabo tem uma forma física de acordo com o imaginário cristão: possui chifres, olhos vermelhos e rabo de serpente - o que está em conformidade com a doutrinação recebida por Teodorico Raposo na companhia da tia Patrocínio, desde a infância. No entanto, em Jerusalém, é na companhia do diabo que o leitor o encontrará, junto com a amante Adélia e a inglesinha Mary, ou assistindo, a distância, a crucificação de Jesus Cristo, condenando-o por proibir aos homens os prazeres carnais. O diabo não lhe impõe medo, e está associado à luxúria, à vida livre. O Oriente foi representado como o lugar das delícias, longe da vigilância religiosa e moral ocidental, especialmente a cristã católica, de onde Teodorico se originava.

Já em OMandarim, o diabo se personifica como um homem comum, destituído de formas animalescas, assumindo, talvez, um dos seus disfarces: de um homem galante, vestido de preto. Simboliza, dessa vez, não a sexualidade, mas o apego à riqueza, que pode ser obtida da forma mais fácil, não importa se a personagem tenha que tocar uma campainha e matar um mandarim na China. Nessa narrativa, Eça de Queirós problematizou um tema constante em sua produção literária: o binônio ociosidade/açãoª , pelo qual chama a atenção do leitor, mesmo se utilizando da retórica e/ou do disfarce da ironia, para que a realidade não seja negada em favor da fantasia, para que o trabalho suplante a inatividade.

\footnotetext{
${ }^{3}$ Para conhecer mais a discussão que realizei sobre a tese ociosidade/ação, ver minha tese de doutorado $\mathbf{O}$ corpo e a voz - Inscrições sobre o masculino em narrativas queirosianas, defendida na Universidade Federal de Minas Gerais - UFMG, em 2002.
} 
Tanto em $A$ relíquia quanto em $O$ mandarim temos duas contundentes reflexões sobre a realidade histórica de Portugal no final do século XIX. Na primeira narrativa, Eça de Queirós problematiza a influência negativa da religião na formação do povo português, se não alienante, pelo menos ineficiente e teórica, fantasiosa e hipócrita. Na segunda narrativa, o autor desconstrói o imaginário seiscentista do Oriente como um lugar exótico, paradisíaco e de enriquecimento fácil, considerado pelos europeus como lugar de bárbaros, sem cultura e de livre exploração econômica.

\section{Referências}

ARAÚJO, L. M. de. O Egito na obra de Eça de Queiroz. In MATOS, A. Campos. Dicionário de Eça de Queiroz. Lisboa: Editorial Caminho, 1988.

BíBLIA de Estudo Vida. A.T. Isaías. 2a reimpressão. São Paulo: Editora Vida, 1999. Cap. 62, p. 1152-1153.

BUENO, A. de F. As Imagens de Cristo na Obra de Eça de Queirós. São Paulo: Unicamp, 2000. (tese de doutorado).

CHEVALIER, Jean; GHEERBRANT, A. Dicionário de Símbolos - Mitos, sonhos, costumes, gestos, formas, figures, cores, números. Rio de Janeiro: José Olympio, 1997.

GARCEZ, M. H. N. Visões de Jerusalém. In OLIVEIRA, S. M. P. de. ANAIS do XVII Encontro de Professores Universitários de Literatura Portuguesa. Belo Horizonte: FALE/UFMG/PUC/MINAS, 2001.

LOPES, Ó. Jesus e o diabo. In: $\mathbf{1 5 0}$ anos com Eça de Queirós: Anais do III encontro internacional de queirosianos. São Paulo: Centro de Estudos Portugueses da USP, 1997. 463-468.

LIMA, I. P. de. O Orientalismo na Literatura Portuguesa: Reelaboração moderna do mito. In. DUARTE, L. M. P.; OLIVEIRA, P. F. da M. de; OLIVEIRA, S. M. P. de. ANAIS do XVII Encontro de Professores Universitários de Literatura Portuguesa. Belo Horizonte: FALE/UFMG/PUC/MINAS, 2001.

MATOS, A. C. Dicionário de Eça de Queiroz. Lisboa: Editorial Caminho, 1988.

NAZARIO, L. (org.) A Cidade Imaginária. São Paulo: Perspectiva, 2005.

NOGUEIRA, C. R. F. O diabo no imaginário cristão. São Paulo: Ática, 1986.

Interdisciplinar, Sằo Cristóvầo, UFS, v. 33, jan-jun, p. 155-171, 2020

D0I: https://doi.org/10.47250/intrell.v33i1.14183 
LEITURAS DE JERUSALÉM E DA CHINA EM DUAS NARRATIVAS DE EÇA DE OUEIRÓS

QUEIRÓS, E. de. A Relíquia. Rio de Janeiro: Click editora, s/d.

SAID, E. Orientalismo. O Oriente como invenção do Ocidente. São Paulo: Companhia das Letras, 2001.

SEQUEIRA, M. do C. C. B. de. A Dimensão fantástica na obra de Eça de Queirós. Porto: Campo das Letras, 2002.

TODOROV, T. Introdução à literatura fantástica. São Paulo: Perspectiva, 1975. 